\title{
Assessment of the Binding of Hydroxylated Polybrominated Diphenyl Ethers to Thyroid Hormone Transport Proteins Using a Site-Specific Fluorescence Probe
}

\author{
Xiao M. Ren and Liang-Hong Guo* \\ State Key Laboratory of Environmental Chemistry and Eco-toxicology, Research Centre for Eco-environmental Sciences, Chinese \\ Academy of Sciences, 18 Shuangqing Road, P.O. Box 2871, Beijing 100085, China
}

\section{Supporting Information}

\begin{abstract}
Polybrominated diphenyl ethers (PBDEs) have been shown to disrupt thyroid hormone $(\mathrm{TH})$ functions on experimental animals, and one of the proposed disruption mechanisms is the competitive binding of PBDE metabolites to $\mathrm{TH}$ transport proteins. In this report, a nonradioactive, site-specific fluorescein-thyroxine (F-T4) conjugate was designed and synthesized as a fluorescence probe to study the binding interaction of hydroxylated PBDEs to thyroxine-binding globulin (TBG) and transthyretin (TTR), two major $\mathrm{TH}$ transport proteins in human plasma. Compared with free $\mathrm{F}-\mathrm{T} 4$, the fluorescence intensity of TTR-bound conjugate was enhanced by as much as 2 -fold, and the fluorescence polarization value of TBGbound conjugate increased by more than 20 -fold. These changes provide signal modulation mechanisms for $\mathrm{F}-\mathrm{T} 4$ as a fluorescence probe. Based on fluorescence quantum yield and lifetime measurements, the fluorescence intensity enhancement was likely due to the elimination of intramolecular fluorescence quenching of fluorescein by $\mathrm{T} 4$ after F-T4 was bound to TTR. In circular

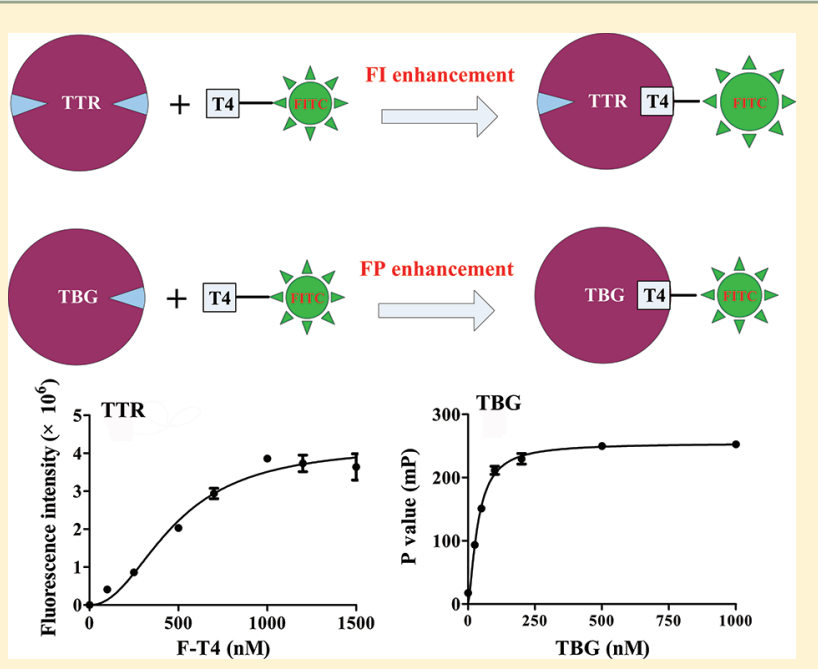
dichroism and intrinsic tryptophan fluorescence measurements, F-T4 induced similar spectroscopic changes of the proteins as $\mathrm{T} 4$ did, suggesting that $\mathrm{F}-\mathrm{T} 4$ bound to the proteins at the $\mathrm{T} 4$ binding site. By using $\mathrm{F}-\mathrm{T} 4$ as the fluorescence probe in competitive binding assays, $11 \mathrm{OH}-\mathrm{PBDEs}$ with different levels of bromination and different hydroxylation positions were assessed for their binding affinity with TBG and TTR, respectively. The results indicate that the binding affinity generally increased with bromine number and $\mathrm{OH}$ position also played an important role. 3-OH-BDE-47 and 3'-OH-BDE-154 bound to TTR and TBG even stronger, respectively, than T4. With rising environmental level and high bioaccumulation capability, PBDEs have the potential to disrupt thyroid homeostasis by competitive binding with $\mathrm{TH}$ transport proteins.
\end{abstract}

\section{INTRODUCTION}

Polybrominated diphenyl ethers (PBDEs) have been widely used over the past few decades as flame retardant additives in plastic materials, paints, textile fabrics, and so forth. As a result, rising levels of PBDEs have been found in the bodies of humans and wildlife. ${ }^{1,2}$ In addition, hydroxylated PBDEs (OH-PBDEs) have also been detected, which can be of natural origin and/or of metabolically derived biotransformation of PBDEs. ${ }^{3-6}$ In 2009, commercial pentabromodiphenyl ether and octabromodiphenyl ether were added to the list of persistent organic pollutants of the Stockholm Convention because of their potential risks to human health and the environment. Furthermore, Bromine Science and Environmental Forum (BSEF) members stated that they would voluntarily cease the production of decaPBDE by $2013 .^{7}$ In spite of all these policies and bans, due to their characteristics of persistence in the environment and bioaccumulation and bioamplification through the food web, even low level PBDEs in the environment might pose great risks to human health and the ecological systems. ${ }^{8,9}$ The mechanisms involved in thyroid homeostasis are numerous and complex. Endogenous thyroid hormones (THs), including thyroxine (T4) and triiodothyronine (T3), are essential for the modulation of growth and differentiation of many organs, as well as the energy homeostasis and numerous key metabolic pathways. ${ }^{10}$ There are at least three different levels at which PBDEs may interfere with thyroid homeostasis: at the receptor level, in THs metabolism, and in THs transport in the bloodstream. ${ }^{1,8}$ Thyroxine-binding globulin (TBG) and transthyretin (TTR) are the two major THs transport proteins in human plasma, ${ }^{11,12}$ responsible for $75 \%$ and $20 \%$ of $\mathrm{T} 4$ binding activity, respectively. ${ }^{13}$ Competitive binding of PBDEs with

Received: January 3, 2012

Revised: March 20, 2012

Accepted: March 22, 2012

Published: April 6, 2012 
transport proteins in vivo would displace THs from the proteins and disturb the normal level of THs in the bloodstream. ${ }^{14}$ In fact, some animal studies found that plasma THs levels changed significantly after exposure to PBDEs. ${ }^{15,16}$ The end points of the disruption of THs levels were likely to be abnormal thyroid function, neuron-developmental deficits, and cancer. ${ }^{9}$ It is therefore worthwhile to investigate the binding of PBDEs with THs transport proteins as a potential disruption mechanism of thyroid functions.

To quantitatively evaluate the binding of PBDEs to transport proteins, various analytical methods have been developed. One of the most conventional methods is the radio-labeled ligand displacement method, which uses ${ }^{125} \mathrm{I}$ labeled $\mathrm{T} 4$ as the radiotracer in a competitive binding assay. By using this method, a number of research groups revealed that, although most PBDEs bound to TTR and TBG very weakly, some OHPBDEs showed very high binding potency. ${ }^{17,18}$ This was attributed to the close structural resemblance of OH-PBDEs with THs. However, the radio-labeled method has some disadvantages. The measurement requires physical separation between protein-bound and free ${ }^{125} \mathrm{I}-\mathrm{T} 4$, which is a practical inconvenience and a potential source of deviation from equilibrium. ${ }^{19}$ Radio-labeled materials are often costly and also present a safety hazard. Therefore, alternative methods suitable for competitive binding studies are desired. Lately, a surface plasmon resonance (SPR) biosensor-based method for screening chemicals with $\mathrm{T} 4$ transport disrupting activity was developed. $^{20,21}$ The method is label-free and monitors the binding event in real time. The binding affinities of 62 chemicals including a few PBDEs and their metabolites were examined. The results are consistent with the findings in radiolabeled assays in that the hydroxylated PBDEs (OH-PBDEs) have high affinity for TTR. However, SPR is a surface-based measurement and may not represent the binding reaction in homogeneous solutions. Fluorescence competitive binding assay is another extensively used method to study the ligand-receptor interaction. The most distinctive feature of the method is its homogeneous format, which simulates more closely biological systems and also makes the measurement very simple and convenient to perform. A fluorescent probe, 8-anilinonaphthalene-1-sulfonate (ANS), has also been applied in competitive fluorescence assays to determine the affinities of THs to transport proteins. ${ }^{22,23}$ Our previous work also investigated the binding potency of $14 \mathrm{OH}-\mathrm{PBDEs}$ by this method, and revealed some structural characteristics of the binding interaction between $\mathrm{OH}-\mathrm{PBDEs}$ and transport proteins. $^{24}$ One drawback of the method is that ANS is known to bind to many proteins by nonselective hydrophobic forces and therefore cannot be used to explore the ligand binding sites specifically. Since many proteins have more than one ligand-binding site, a fluorescence probe with binding site specificity is extremely important for studying the binding effect of ligands to target proteins.

Covalent conjugation (chemical bond linkage) of a fluorophore with an endogenous ligand is an applicable strategy to produce site-specific fluorescent probes. Protein binding can be monitored by the change of the fluorescence properties of the conjugate, that is, fluorescence intensity, excitation or emission peak wavelength, or fluorescence polarization. Fluorescein, one of the most commonly used fluorescent dyes, has been conjugated with various ligands to study the interaction of endogenous and xenobiotic chemicals with target proteins. For example, a fluorescein-estradiol conjugate was developed to study the interaction of endocrine disruptors with the estrogen receptor. ${ }^{25}$ A fluorescein-chenodeoxycholic acid (CDCA) was applied to discover inhibitors against the Farnesoid $\mathrm{X}$ receptorCDCA interaction. ${ }^{26}$ Conjugation of fluorescein with the synthetic ligands GC-1 and $\mathrm{NH}-2$ and the natural ligand $\mathrm{T} 3$ were synthesized as thyroid hormone receptor (TR)-targeting probes for ligand binding. ${ }^{27}$

In the present study, a fluorescein-thyroxine (F-T4) conjugate was designed, synthesized, and characterized as a sitespecific fluorescence probe for competitive binding assays with $\mathrm{TH}$ transport proteins. The conjugate was employed to evaluate the binding affinity of $11 \mathrm{OH}-\mathrm{PBDE}$ with TBG and TTR, and the effect of bromination level and $\mathrm{OH}$ position on the binding affinity was also investigated.

\section{EXPERIMENTAL SECTION}

Chemicals. Human TTR and TBG were purchased from Calbiochem (San Diego, CA, USA). Triiodothyronine (T3) and thyroxine (T4) were purchased from Fitzgerald Industries International, Inc. (Concord, MA, USA). Fluorescein isothiocyanate (FITC) was from Merck (KGaA, Darmstadt, Germany). Size-exclusion gel Sephadex G-75 was from GE Healthcare Bio-Sciences AB (Björkgatan, Uppsala, Sweden). Deionized water was prepared from a Millipore Milli-Q system (Bedford, MA, USA). Eleven monohydroxylated PBDEs, 2'-hydroxy4-monobromodiphenyl ether (2'-OH-BDE-3), 2'-hydroxy-2,4dibromodiphenyl ether (2'-OH-BDE-7), 3'-hydroxy-2,4-dibromodiphenyl ether (3'-OH-BDE-7), 2'-hydroxy-2,4,4'-tribromodiphenyl ether (2'-OH-BDE-28), 3'-hydroxy-2,4,4'-tribromodiphenyl ether (3'-OH-BDE-28), 3-hydroxy-2,2',4,4'-tetrabromodiphenyl ether (3-OH-BDE-47), 5-hydroxy-2,2',4,4'tetrabromodiphenyl ether (5-OH-BDE-47), 6-hydroxy-2,2',4,4'tetrabromodiphenyl ether (6-OH-BDE-47), 3-hydroxy2,2',4,4',6-pentabromodiphenyl ether (3-OH-BDE-100), 3'hydroxy-2,2',4,4',5,6-hexabromodiphenyl ether (3'-OH-BDE154), and 4-hydroxy-2,2',3,4',5,6,6'-heptabromodiphenyl ether (4-OH-BDE-188), were purchased from AccuStandard (New Haven, CT, USA). All the $\mathrm{OH}-\mathrm{PBDEs}$ were dissolved in acetonitrile with the concentration of $50 \mu \mathrm{g} / \mathrm{mL}$ or $10 \mu \mathrm{g} / \mathrm{mL}$. The structures of these chemicals are listed in Figure 1.

Fluorescence Probe Synthesis. The fluorescence probe F-T4 was prepared according to a method previously reported. $^{28}$ One volume of $20 \mathrm{mg} / \mathrm{mL}$ FITC was reacted with 2 volumes of $20 \mathrm{mg} / \mathrm{mL} \mathrm{T} 4$ in a pyridine/water/ triethylamine medium $(9: 1.5: 0.1, \mathrm{v} / \mathrm{v} / \mathrm{v})$ for $1 \mathrm{~h}$ at $37{ }^{\circ} \mathrm{C}$. Crude products were then precipitated with 20 volumes of 0.2 $\mathrm{M}$ ammonium acetate buffer, $\mathrm{pH} 4.0$, and collected by centrifugation $(10 \mathrm{~min}, 1000 \mathrm{~g})$. The precipitate was washed by suspending in 20 volumes of distilled water followed by centrifugation as before. The product was then redissolved in 5 volumes of $0.05 \mathrm{M} \mathrm{NH}_{4} \mathrm{HCO}_{3}$ and applied to a Sephadex G-75 fine column $(3 \times 25 \mathrm{~cm})$ equilibrated with $0.05 \mathrm{M} \mathrm{NaHCO}_{3}$, $\mathrm{pH}$ 8.5. The impurities were removed from the column by passing 10 column volumes of $0.05 \mathrm{M} \mathrm{NH}_{4} \mathrm{HCO}_{3}$. The desired product was then eluted from the column with distilled water and freeze-dried to a yellow powder, stored desiccated at $-20{ }^{\circ} \mathrm{C}$. The synthetic product was found to possess the correct molecular weight of 1165.7 as determined by an Agilent $6100 \mathrm{LC} / \mathrm{MS}$ (Santa Clara, CA, USA). A stock solution of $24 \mu \mathrm{M}$ was prepared in Tris- $\mathrm{NaCl}$ buffer $(50 \mathrm{mM}$ Tris $-\mathrm{HCl} / 100 \mathrm{mM}$ $\mathrm{NaCl}, \mathrm{pH}$ 7.4). Its concentration was determined by measuring the absorbance at $490 \mathrm{~nm}$ with the molar extinction coefficient of $7.8 \times 10^{4} \mathrm{M}^{-1} \mathrm{~cm}^{-1}$. 
<smiles>NC(Cc1cc(I)c(Oc2ccc(O)c(I)c2)c(I)c1)C(=O)O</smiles>

T3<smiles>Oc1ccccc1Oc1ccc(Br)cc1</smiles>

2'-OH-BDE-3

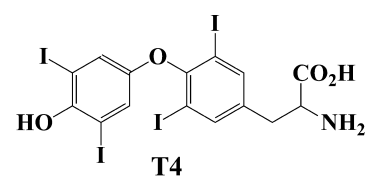

T4
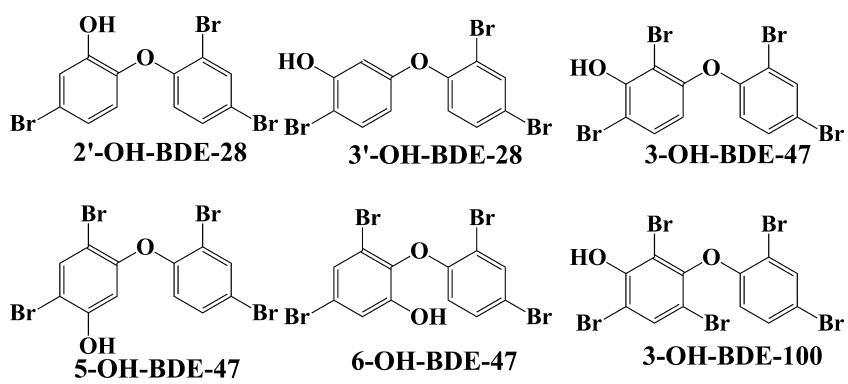<smiles>Oc1c(Br)cc(Br)c(Oc2cc(Br)c(Br)cc2Br)c1Br</smiles>

3'-OH-BDE-154

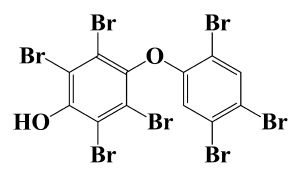

4-OH-BDE-188
Figure 1. Structures of the compounds used in the experiments.

Spectroscopic Measurements. Steady-state fluorescence was measured on a Horiba Fluoromax-4 spectrofluorimeter (Edison, NJ, USA). The excitation wavelength was 490 and $280 \mathrm{~nm}$, respectively, for F-T4 and tryptophan (Trp). For fluorescence polarization measurements, F-T4 was excited with vertically polarized $490 \mathrm{~nm}$ light, and its vertical $\left(I_{\|}\right)$and horizontal $\left(I_{\perp}\right)$ fluorescence emission intensities at $518 \mathrm{~nm}$ were measured. The polarization value, indicated in millipolarization units $(\mathrm{mP})$, was calculated according to the following equation: ${ }^{27}$

$$
\mathrm{mP}=10^{3} \times\left(I_{||}-I_{\perp}\right) /\left(I_{\|}+I_{\perp}\right)
$$

Fluorescence lifetime experiments were performed on an Edinburgh Instruments Lifespec spectrofluorimeter (Kirkton Campus, Livingston, UK). A $372 \mathrm{~nm}$ laser with $62 \mathrm{~mW}$ power was used as the excitation light. The decay curves were fitted with a single-exponential function to obtain the fluorescence lifetime.

Circular dichroism (CD) spectra were taken on a JASCO J-815 spectropolarimeter (JASCO Inc., Tokyo, Japan) in a $1 \mathrm{~mm}$ cuvette (Hellma, Müllheim, Germany). Spectra were recorded with a $2 \mathrm{~nm}$ bandwidth, $50 \mathrm{~nm} / \mathrm{min}$ scan rate, and $1 \mathrm{~s}$ time constant. UV-visible absorption spectra were measured on an Agilent 8453 UV-vis spectrophotometer (Santa Clara, CA, USA).

Direct Fluorescent Ligand Binding Assay. Direct fluorescent ligand binding measurements were performed to measure the dissociation constant $\left(K_{\mathrm{d} \text {,probe }}\right)$ of F-T4 with TTR and TBG. For TTR, different volumes of F-T4 were added from the stock solution to $1 \mu \mathrm{M}$ TTR to obtain the required concentration. After being allowed to stand for $5 \mathrm{~min}$ at room temperature, the fluorescence emission spectrum of each solution was recorded. The intensity at $518 \mathrm{~nm}$ (corrected for background from free F-T4) was plotted as a function of total F-T4 concentration. For TBG, various concentrations of the protein $(25-1000 \mathrm{nM})$ were titrated into $50 \mathrm{nM} \mathrm{F}-\mathrm{T} 4$. After being allowed to stand for $5 \mathrm{~min}$ at room temperature, each sample was subjected to fluorescence polarization measurement. The polarization value at $518 \mathrm{~nm}$ was plotted as a function of TBG concentration. The $K_{\mathrm{d} \text {,probe }}$ values of F-T4 with TTR and TBG were then calculated by nonliner regression curve-fitting of the binding data using the Graphpad Prism software.

Competitive Binding Assay. Competitive binding assays were carried out to investigate the affinity of $\mathrm{THs}$ and $\mathrm{OH}-$ PDBEs with TTR and TBG, respectively. T4 and T3 stock solutions were prepared by dissolving the solids in Tris- $\mathrm{NaCl}$ buffer with the help of ammonia. The T4 concentration was determined by measuring the absorbance at $325 \mathrm{~nm}$ with a molar extinction coefficient $(\varepsilon)$ of $6.18 \times 10^{3} \mathrm{M}^{-1} \mathrm{~cm}^{-1}$, while $\mathrm{T} 3$ was determined at $320 \mathrm{~nm}$ with $\varepsilon=4.66 \times 10^{3} \mathrm{M}^{-1} \mathrm{~cm}^{-1}$.

For the TTR competitive binding assay, $200 \mathrm{nM}$ TTR and $100 \mathrm{nM} \mathrm{F}-\mathrm{T} 4$ were mixed in a total volume of $80 \mu \mathrm{L}$ and incubated for $5 \mathrm{~min}$ at room temperature. Then, $10 \mu \mathrm{L}$ of ligand of different concentration in a buffer containing less than $10 \%$ acetonitrile was added and incubated for $5 \mathrm{~min}$. The fluorescence intensity at $518 \mathrm{~nm}$ before and after ligand addition was measured, and the relative fluorescence intensity was plotted as a function of ligand concentration. For the TBG competitive binding assay, $180 \mathrm{nM}$ TBG, $45 \mathrm{nM} \mathrm{F-T4,} \mathrm{and}$ different concentrations of the ligand were mixed in a total volume of $90 \mu \mathrm{L}$ and incubated for $5 \mathrm{~min}$ at room temperature. Then, the fluorescence polarization at $518 \mathrm{~nm}$ was measured and plotted as a function of ligand concentration. The content of acetonitrile in the final solution was kept below $1.2 \%$ to avoid solvent effect. The competition curves were fitted with a sigmoidal model (OriginLab, Northampton, MA, USA) to derive an $\mathrm{IC}_{50}$ value (the concentration of the ligand required to displace half of the probe from the protein).

The dissociation constants $K_{\mathrm{d} \text {,ligand }}$ of the examined compounds with the transport proteins were then calculated according to the following equation: ${ }^{29}$

$$
\mathrm{IC}_{50} /[\mathrm{F}-\mathrm{T} 4]_{\text {total }}=K_{\mathrm{d} \text {,ligand }} / K_{\mathrm{d} \text {,probe }}
$$

where $[\mathrm{F}-\mathrm{T} 4]_{\text {total }}$ is the total concentration of $\mathrm{F}-\mathrm{T} 4$.

\section{RESULTS AND DISCUSSION}

Signal Enhancement of Fluorescent Probe upon Binding to Transport Proteins. The F-T4 conjugate was designed and synthesized as a potential fluorescence probe for $\mathrm{T} 4$ targeting proteins. It was hoped that the T4 moiety of the conjugate would provide site specificity for proteins, whereas the fluorescein group served as a signal reporter. One of the requirements for a fluorescent probe is signal modulation after binding with the target protein, which can be a change in its fluorescence intensity, emission wavelength, or degree of polarization.

When excited with $490 \mathrm{~nm}$ light, free F-T4 displayed a fluorescence emission peak at $518 \mathrm{~nm}$. After addition of the transport proteins, the peak intensity increased by 2.3 -fold for TTR and 1.3-fold for TBG (Figure 2). In a control experiment, ovalbumin (OVA), a protein that does not bind with T4, was added into an F-T4 solution. The fluorescence did not change at all, indicating that the signal increase with the transport proteins was due to the specific interaction between $\mathrm{F}-\mathrm{T} 4$ and the protein. Therefore, the modulation of fluorescence intensity 


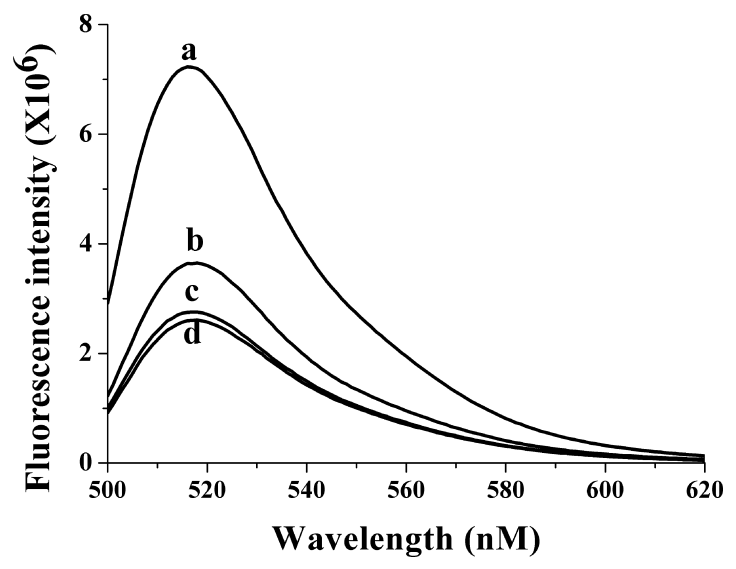

Figure 2. Fluorescence emission spectra of $1 \mu \mathrm{M} \mathrm{F}-\mathrm{T} 4$ in (a) $1 \mu \mathrm{M}$ TTR, (b) $1 \mu \mathrm{M}$ TBG, (c) buffer, and (d) $1 \mu \mathrm{M}$ OVA.

can be used to detect the binding of $\mathrm{F}-\mathrm{T} 4$ to $\mathrm{T} 4$ transport proteins. In a previous report, $\mathrm{F}-\mathrm{T} 4$ was used as a fluorescent tracer in the immunoassay of $\mathrm{T} 4$, and fluorescence enhancement was also observed after the tracer formed immunocomplex with anti-T4 antibody. ${ }^{28}$

In addition to the modulation of fluorescence intensity, change of fluorescence polarization (FP) can also be used to detect the binding of fluorescence probes with proteins. When a fluorescent molecule is excited with a plane-polarized light, the emission light can be in a different plane, and the angle between the two planes is expressed as FP. FP depends on the rotational relaxation time. A small molecule, such as free F-T4, rotates quickly in solution and produces a low polarization value. A large fluorescent molecule, such as protein-bound $\mathrm{F}-\mathrm{T} 4$, rotates slowly during the excited state and produces a high polarization value. Therefore, the free and protein-bound fluorescent probe can be differentiated by the polarization value. In the FP measurement, the polarization value of $\mathrm{F}-\mathrm{T} 4$ increased significantly from $10 \mathrm{mP}$ to $276 \mathrm{mP}$ and $203 \mathrm{mP}$ once TTR and TBG were added, reflecting the binding of F-T4 to the transport proteins. No increase was noted for $\mathrm{F}-\mathrm{T} 4$ in ovalbumin. Both the fluorescence emission and fluorescence polarization measurements indicated that $\mathrm{F}-\mathrm{T} 4$ interacted with the two transport proteins in a specific manner.

To further understand the mechanism of $\mathrm{F}-\mathrm{T} 4$ fluorescence enhancement, fluorescence quantum yields (QY) and lifetimes of FITC, F-T4, and protein-bound F-T4 were measured. Fluorescence quantum yield, an indicator for the efficiency of the fluorescence process, is defined as the ratio of the number of photons emitted to the number of photons absorbed. In our experiments, relative $\mathrm{QY}$ was obtained by dividing the integrated area of the fluorescence emission peak by the optical absorbance of the same solution. Therefore, the relative QY was calculated to be $1.3( \pm 0.2) \times 10^{9}, 3.9( \pm 1.7) \times 10^{8}, 7.9$ $( \pm 1.2) \times 10^{8}$, and $5.5( \pm 0.4) \times 10^{8}$ for FITC, F-T4, TTRbound F-T4, and TBG-bound F-T4, respectively. Obviously, the yield decreased when the fluorophore was covalently attached to $\mathrm{T} 4$ but recovered substantially after F-T4 was bound to $\mathrm{TH}$ transport proteins. A similar trend was observed in the fluorescence lifetime measurements (see Figure S2, Supporting Information). Fluorescence intensity of the four compounds all decreased rapidly over time, and the change could be fitted with a single-exponential function. From the fitted curves, fluorescence lifetimes were estimated to be 3.86, 2.80, 3.85, and 3.13 ns for FITC, F-T4, TTR-bound F-T4, and TBG-bound F-T4, respectively. The two sets of experimental data suggest that there exists a process of intramolecular fluorescence quenching in the $\mathrm{F}-\mathrm{T} 4$ conjugate, probably by the iodine atoms of T4. Fluorescence quenching reduces the emission intensity of fluorescein and shortens its lifetime. When the conjugate is bound to a protein, the iodine atoms are enclosed inside the protein-binding pocket, and close contact between the quencher and fluorophore is prohibited. As a result, both the fluorescence intensity and lifetime are restored.

Site-Specificity of Fluorescence Probe to Transport Proteins. Apart from signal modulation, another requirement for the fluorescent probe is its site-specificity in protein binding. For the F-T4 conjugate we synthesized in this study, FITC was attached directly to the amino group of T4. It was inferred that $\mathrm{F}-\mathrm{T} 4$ would bind to transport proteins at the $\mathrm{T} 4$ binding sites. To evaluate the site specificity of $\mathrm{F}-\mathrm{T} 4$ binding to proteins, the interaction was investigated by intrinsic Trp fluorescence and CD spectroscopy. Trp fluorescence is very sensitive to its microenvironment, a characteristic that made it an invaluable and popular tool for studying protein conformational change. ${ }^{30}$ When excited at $280 \mathrm{~nm}$, TTR and TBG exhibited fluorescence emission maxima at 350 and $340 \mathrm{~nm}$, respectively. Upon addition of $5 \mu \mathrm{M}$ T4, Trp fluorescence intensity of TTR decreased by about $46 \%$ (Figure 3A). This can be attributed to the binding of T4 to TTR, which resulted in a conformational change of the protein. When T4 was replaced with $\mathrm{F}-\mathrm{T} 4$, the change of fluorescence spectrum was almost the same as $\mathrm{T} 4$, suggesting that $\mathrm{F}-\mathrm{T} 4$ and $\mathrm{T} 4$ target the same binding site on TTR. Similar results were observed with TBG (Figure 3B), suggesting that F-T4 binds to TBG also at the same binding site as $\mathrm{T} 4$.

CD spectroscopy is also a very useful tool in studying ligand-protein binding interaction. CD spectrum in the far-UV region $(195-250 \mathrm{~nm})$ is a function of a protein's secondary structures including $\alpha$-helices, $\beta$-sheets, and random coils. Ligand binding usually induces protein conformational changes that lead to changes in $\mathrm{CD}$ spectra. Figure $3 \mathrm{C}$ shows the $\mathrm{CD}$ spectrum of $5 \mu \mathrm{M}$ TTR, which is composed of a broad negative peak at $214 \mathrm{~nm}$ and a sharp positive peak at $198 \mathrm{~nm}$. After T4 binding, the molar ellipticity value at $198 \mathrm{~nm}$ increased from 5 mdeg to $15 \mathrm{mdeg}$, while the negative peak remained unchanged. Addition of F-T4 to TTR resulted in the same change in the CD spectrum as T4. For TBG, no change of CD spectra was detected with either T4 or F-T4 (Figure 3D). The above fluorescence and $\mathrm{CD}$ experimental data suggest that F-T4 interacts with TTR and TBG at the same binding site as $\mathrm{T} 4$ and therefore can be used as a site-specific probe in competitive protein binding assays.

Assessment of $\mathrm{OH}-\mathrm{PBDE}$ Binding Affinity with TTR and TBG. To establish a competitive binding assay, the binding constant of the probe ( $\mathrm{F}-\mathrm{T} 4)$ with the target proteins (TTR and TBG) needs to be determined first. The increase of F-T4 fluorescence intensity after binding with TTR was used in a direct ligand binding assay to determine the binding constant. In the assay, TTR with a fixed concentration $(1 \mu \mathrm{M})$ was incubated with different concentrations of F-T4. As depicted in Figure 4A, the fluorescence intensity at $518 \mathrm{~nm}$ increased with increasing concentration of $\mathrm{F}-\mathrm{T} 4$ and reached the saturation point at $1.1 \mu \mathrm{M}$. At higher $\mathrm{F}-\mathrm{T} 4$ concentrations, fluorescence actually decreased. As TTR has two T4 binding sites, the signal decrease at molar ratios higher than 1 is tentatively attributed to self-quenching by the second F-T4. 

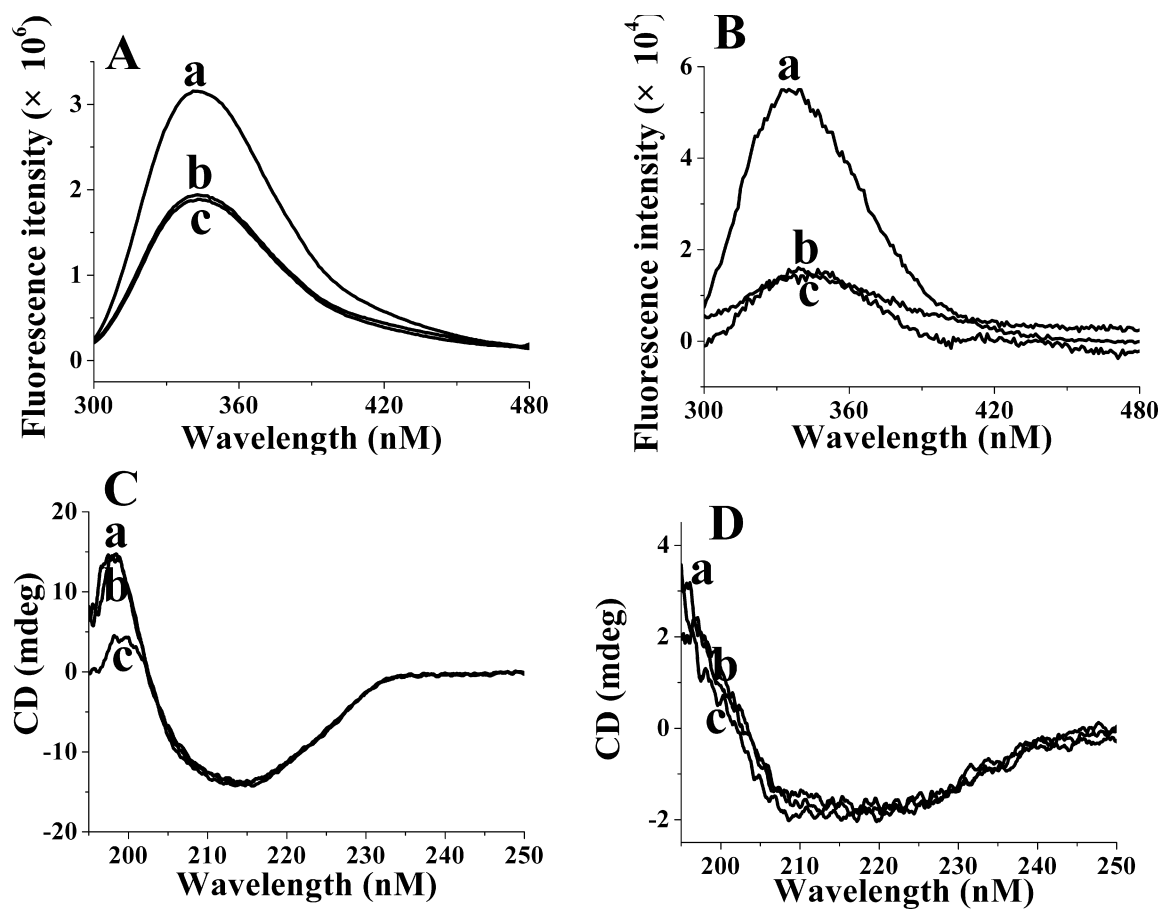

Figure 3. (A) Tryptophan fluorescence emission spectra of (a) $5 \mu \mathrm{M}$ TTR, (b) $5 \mu \mathrm{M}$ TTR $+5 \mu \mathrm{M}$ T4, and (c) $5 \mu \mathrm{M} \mathrm{TTR}+5 \mu \mathrm{M}$ F-T4; (B) Tryptophan fluorescence emission spectra of (a) $1 \mu \mathrm{M} \mathrm{TBG}$, (b) $1 \mu \mathrm{M} \mathrm{TBG}+1 \mu \mathrm{M} \mathrm{T} 4$, and (c) $1 \mu \mathrm{M} \mathrm{TBG}+1 \mu \mathrm{M} \mathrm{F}-\mathrm{T} 4$; (C) CD spectra of (a) $5 \mu \mathrm{M}$ TTR $+5 \mu \mathrm{M}$ T4, (b) $5 \mu \mathrm{M}$ TTR $+5 \mu \mathrm{M}$ F-T4, and (c) $5 \mu \mathrm{M}$ TTR; (D) CD spectra of (a) $1 \mu \mathrm{M} \mathrm{TBG,} \mathrm{(b)} 1 \mu \mathrm{M}$ TBG $+1 \mu \mathrm{M} \mathrm{T} 4$, and (c) $1 \mu \mathrm{M}$ TBG $+1 \mu \mathrm{M} \mathrm{F}-\mathrm{T} 4$.
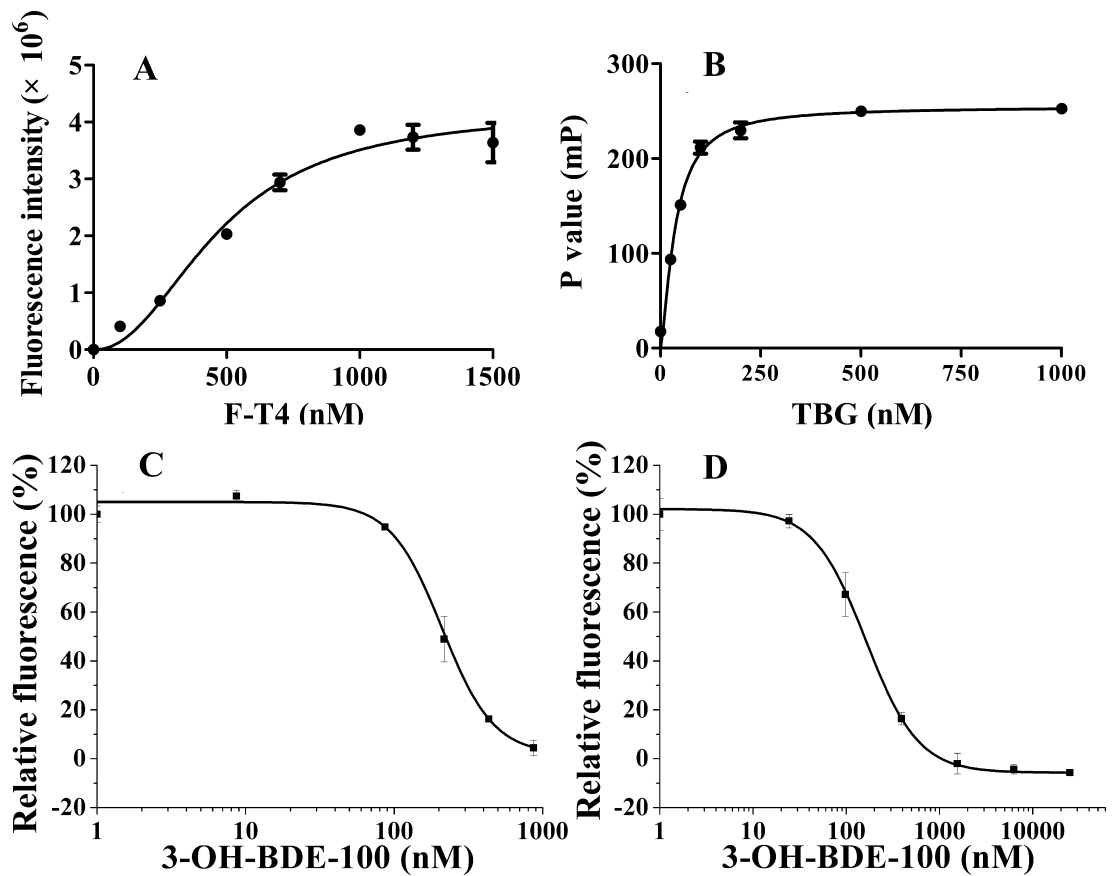

Figure 4. Direct fluorescence binding curves and competitive fluorescence binding curves. (A) Background subtracted fluorescence intensity of $\mathrm{F}-\mathrm{T} 4$ at $518 \mathrm{~nm}$ as a function of $\mathrm{F}-\mathrm{T} 4$ concentration added into a solution of $1 \mu \mathrm{M}$ TTR; (B) Fluorescence polarization value of $1 \mu \mathrm{M} \mathrm{F}-\mathrm{T} 4$ at $518 \mathrm{~nm}$ as a function of added TBG concentration; (C) Relative fluorescence intensity of F-T4 at $518 \mathrm{~nm}$ in $180 \mathrm{nM}$ TTR as a function of added 3-OH-BDE-100 concentration; and (D) Relative fluorescence polarization value of F-T4 at $518 \mathrm{~nm}$ in $180 \mathrm{nM}$ TBG as a function of added 3-OH-BDE-100 concentration. The error bars represent the standard deviation of three independent measurements.

By using the binding data, a $K_{\mathrm{d}}$ value of $92 \pm 4 \mathrm{nM}\left(R^{2}=0.98\right)$ was obtained between F-T4 and TTR.

Although the addition of TBG into an F-T4 solution also lead to an increase in fluorescence intensity (Figure 2A), the $30 \%$ increase is not large enough for a reliable ligand binding assay. On the other hand, fluorescence polarization increased by as much as 10 -fold and was therefore used to measure the binding constant of F-T4 with TBG. Figure 4B illustrates the dependence of fluorescence polarization as a function of TBG concentration. From the binding curve, a $K_{d}$ value of 
$17 \pm 2 \mathrm{nM}\left(R^{2}=0.99\right)$ was determined between $\mathrm{F}-\mathrm{T} 4$ and TBG.

After the dissociation constants of F-T4 with TTR and TBG were determined, the binding potency of 11 commercially available $\mathrm{OH}-\mathrm{PBDEs}$ with TTR and TBG was assessed quantitatively by competitive fluorescence intensity and fluorescence polarization binding assays, respectively. It was done by adding a series of concentrations of an $\mathrm{OH}-\mathrm{BDE}$ into a mixture solution containing $\mathrm{F}-\mathrm{T} 4$ and a transport protein with constant concentrations. As $\mathrm{OH}-\mathrm{BDE}$ concentration was increased, more protein-bound $\mathrm{F}-\mathrm{T} 4$ was displaced, leading to fluorescence signal reduction (Figure 4C, D and Figures S1 and S2 in the Supporting Information). The binding constant of the $\mathrm{OH}-\mathrm{BDEs}$ was then calculated using the $\mathrm{IC}_{50}$ value from the competition curve and eq 2 . All the measured $\mathrm{IC}_{50}, K_{\mathrm{d}}$, and $\mathrm{RP}$ (relative potency) values for the $11 \mathrm{OH}-\mathrm{PBDEs}$ are listed in Tables 1 and 2. RP is defined as the binding affinity of a

Table 1. $\mathrm{IC}_{50}$ Values, Dissociation Constants $\left(K_{\mathrm{d}}\right)$, and the Relative Potency (RP) of the Two Thyroid Hormones and $11 \mathrm{OH}$-PBDEs Obtained with TTR

\begin{tabular}{lccll}
\multicolumn{1}{c}{ compound } & $\mathrm{IC}_{50}(\mathrm{nM})$ & $K_{\mathrm{d}}(\mathrm{nM})$ & $\mathrm{RP}$ & literature RP \\
$\mathrm{T} 4$ & $260 \pm 13$ & $239 \pm 12$ & 1 & 1 \\
$\mathrm{~T} 3$ & $1600 \pm 75$ & $1472 \pm 69$ & 0.16 & $0.04,^{21} 0.11^{24}$ \\
2'-OH-BDE-3 & $4132 \pm 254$ & $3801 \pm 234$ & 0.06 & $0.15^{24}$ \\
2'-OH-BDE-7 & $864 \pm 30$ & $795 \pm 28$ & 0.3 & $0.3^{24}$ \\
3'-OH-BDE-7 & $375 \pm 19$ & $345 \pm 17$ & 0.69 & $0.6^{24}$ \\
2'-OH-BDE-28 & $900 \pm 45$ & $828 \pm 41$ & 0.29 & $2.9^{24}$ \\
3'-OH-BDE-28 & $360 \pm 18$ & $331 \pm 16$ & 0.72 & $1^{24}$ \\
3-OH-BDE-47 & $110 \pm 8$ & $101 \pm 7$ & 2.36 & $0.8^{21} 4.2^{24}$ \\
5-OH-BDE-47 & $218 \pm 11$ & $201 \pm 10$ & 1.19 & $0.4,^{21} 7.5^{24}$ \\
6-OH-BDE-47 & $323 \pm 10$ & $297 \pm 9$ & 0.81 & $0.2^{21} 2^{24}$ \\
3-OH-BDE-100 & $219 \pm 7$ & $201 \pm 6$ & 1.19 & - \\
3'-OH-BDE-154 & $200 \pm 13$ & $184 \pm 12$ & 1.30 & $2.9^{24}$ \\
4-OH-BDE-188 & $190 \pm 12$ & $175 \pm 11$ & 1.37 & - \\
\hline
\end{tabular}

Table 2. $\mathrm{IC}_{50}$ Values, Dissociation Constants $\left(K_{\mathrm{d}}\right)$, and the Relative Potency (RP) of the Two Thyroid Hormones and 11 OH-PBDEs Obtained with TBG

\begin{tabular}{lllll}
\multicolumn{1}{c}{ compound } & \multicolumn{1}{c}{$\mathrm{IC}_{50}(\mathrm{nM})$} & \multicolumn{1}{c}{$K_{\mathrm{d}}(\mathrm{nM})$} & \multicolumn{1}{c}{$\mathrm{RP}$} & \multicolumn{1}{c}{ literature RP } \\
$\mathrm{T} 4$ & $85 \pm 2$ & $29 \pm 1$ & 1 & 1 \\
$\mathrm{~T} 3$ & $175 \pm 7$ & $59 \pm 2$ & 0.49 & $0.8,^{21} 0.13^{24}$ \\
2'-OH-BDE-3 & $\mathrm{ND}^{a}$ & $\mathrm{ND}^{a}$ & $\mathrm{ND}^{a}$ & $0.004^{24}$ \\
2'-OH-BDE-7 & $12583 \pm 376$ & $4278 \pm 128$ & 0.007 & $0.028^{24}$ \\
3'-OH-BDE-7 & $8000 \pm 271$ & $2720 \pm 92$ & 0.01 & $0.019^{24}$ \\
2'-OH-BDE-28 & $7500 \pm 436$ & $2650 \pm 154$ & 0.011 & $0.054^{24}$ \\
3'-OH-BDE-28 & $1200 \pm 52$ & $408 \pm 18$ & 0.07 & $0.068^{24}$ \\
3-OH-BDE-47 & $250 \pm 9$ & $85 \pm 3$ & 0.34 & $0.08,{ }^{21} 0.08^{24}$ \\
5-OH-BDE-47 & $240 \pm 11$ & $82 \pm 4$ & 0.35 & $0.07,{ }^{21} 0.1^{24}$ \\
6-OH-BDE-47 & $350 \pm 19$ & $119 \pm 6$ & 0.24 & $0.16,^{21} 0.068^{24}$ \\
3-OH-BDE-100 & $145 \pm 6$ & $49 \pm 2$ & 0.59 & - . $^{24}$ \\
3'-OH-BDE-154 & $55 \pm 2$ & $19 \pm 1$ & 1.54 & $0.13^{24}$ \\
4-OH-BDE-188 & $161 \pm 5$ & $55 \pm 2$ & 0.53 & - \\
${ }^{a} \mathrm{ND}=$ not determined. & & & \\
\hline
\end{tabular}

chemical with the transport protein in comparison with $\mathrm{T} 4$ and is obtained by dividing the $\mathrm{IC}_{50}$ of $\mathrm{T} 4$ by that of the chemical. In general, the dissociation constants and RPs of the $11 \mathrm{OH}-$ PBDEs with TTR are in the range 101-3801 nM and 0.062.36, respectively, with $3-\mathrm{OH}-\mathrm{BDE}-47$ showing the lowest dissociation constant and highest binding potency. With TBG, the values are in the range $19-4278 \mathrm{nM}$ and $0.007-1.54$, respectively, with 3'-OH-BDE-154 exhibiting the lowest dissociation constant and highest binding potency.

The binding of $\mathrm{OH}-\mathrm{PBDEs}$ with $\mathrm{TH}$ transport proteins has been studied previously by several research groups. Three THslike OH-PBDEs were evaluated by Meerts et al. with ${ }^{125}$ I-labeled T4. ${ }^{17}$ In another report, ${ }^{31}$ 6-OH-BDE-47 was assessed also with radio-isotope $\mathrm{T} 4$ tracer, with an $\mathrm{RP}$ of 0.26 for TTR. In a follow-up study, ${ }^{32}$ the same group examined BDE-47 and its six hydroxylated metabolites and obtained RP values of 4.0, 3.0, and 0.39 for 3-, 5-, and 6-OH-BDE-47, respectively. In a comprehensive study, ${ }^{21} 62$ chemicals were investigated by surface plasmon resonance biosensors on their binding with TTR and TBG. Among the six OH-PBDEs evaluated, 3-, 5-, and 6-OH-BDE-47 had RP values of 0.8, 0.4, and 0.2 , respectively, for TTR, and 0.08, 0.07, and 0.16, respectively, for TBG. Compared with these results, the RP values with TTR obtained in our study are closer to those measured by the traditional radio-isotope method.

With $11 \mathrm{OH}-\mathrm{PBDEs}$ tested, some structural characteristics of the binding with transport proteins can be analyzed. TTR binding potency was clearly associated with the degree of bromination. For OH-PBDEs with the same hydroxylation position (3-meta $\mathrm{OH}$ ), the RP value increased from 0.69 to 2.36 when the number of bromine atoms increased from 2 to 4 . However, no further increase was observed for penta and hexabromine $\mathrm{OH}-\mathrm{PBDEs}(1.19$ and $1.3 \mathrm{RP}$ of $\mathrm{T} 4$, respectively). Similarly, of the three OH-PBDEs with the hydroxylation position at 2-para $\mathrm{OH}$, the same trend was observed. RP increased from 0.06 to 0.29 when the bromination level increased from mono- to trisubstitution. TTR binding affinity of OH-PBDEs also depends on the position of $\mathrm{OH}$ group. For $\mathrm{OH}-\mathrm{PBDEs}$ with the same level of bromination (tetra-) but with different $\mathrm{OH}$ position, the highest binding potency was observed for $3-\mathrm{OH}-$ followed by 5-OH- and 6-OH-BDE-47. Similarly, for the two dibromo and two tribromo compounds, the one with 3-meta $\mathrm{OH}$ exhibited stronger TTR binding potency than the one with $\mathrm{OH}$ group at 2-para position. Similar structural characteristics were also observed in the binding of OH-PBDEs with another transport protein, TBG. However, the dependence on bromination level is even stronger than TTR, with the binding affinity increasing from two to six bromine compounds. In short, two chemical functionalities (degree of bromionation and position of $\mathrm{OH}-$ ) affected the binding potency of $\mathrm{OH}-$ PBDEs, which is similar to earlier studies with halogenated phenols such as $\mathrm{PCB}^{33}$ and $\mathrm{OH}-\mathrm{PCBs}{ }^{17,21}$ In our previous study, ${ }^{24}$ molecular docking analysis was performed for the interaction between $\mathrm{OH}-\mathrm{PBDEs}$ and TTR. The analysis revealed a ligand-binding channel in TTR that was mostly hydrophobic inside but was positively charged at the channel entrance. As the bromination number of $\mathrm{OH}-\mathrm{PBDE}$ increases, its $K_{\mathrm{ow}}$ becomes significantly larger, leading to stronger hydrophobic interactions with the protein. The positive correlation between TTR binding affinity and bromination number observed in the current study can also be rationalized using the molecular docking results.

Based on our results as well as those of others, many $\mathrm{OH}-$ PBDEs possess comparable or even stronger binding affinity with $\mathrm{TH}$ transport proteins than T4. Currently, the total $\mathrm{OH}-$ PBDEs concentration in human blood is in the range 0.012$0.48 \mathrm{nM}^{3}$ This is very low in comparison with total T4 concentration $(58-161 \mathrm{nM})$. Therefore, displacement of T4 
from transport proteins by $\mathrm{OH}-\mathrm{PBDEs}$ would be insignificant at the current human contamination level. However, a retrospective time-trend study has found about 8 -fold increase of total PBDEs concentration in human serum over a 10 year time span. ${ }^{34}$ If this trend also holds true for $\mathrm{OH}-\mathrm{PBDEs}$, in the next $10-15$ years, $\mathrm{OH}-\mathrm{PBDE}$ accumulation in human blood would reach a level that is equal to about $10 \%$ of total $\mathrm{T} 4$. Given the fact that some of the OH-PBDEs have even stronger binding potency than T4, significant displacement of $\mathrm{T} 4$ from the thyroid hormone transport proteins would occur, leading to disruption of $\mathrm{T} 4$ transport. Furthermore, the $\mathrm{OH}-$ PBDEs may act together with other TTR-binding environmental chemicals and hamper $\mathrm{TH}$ homeostasis at different physiological levels and via multiple related mechanisms. ${ }^{35}$ Admittedly, these estimations are based on our in vitro experimental data and therefore cannot be directly extrapolated to in vivo conditions.

\section{ASSOCIATED CONTENT}

\section{S Supporting Information}

Competitive binding curves of T4, T3, and OH-PBDEs with TTR and TBG and decay of fluorescence intensity plots. This material is available free of charge via the Internet at http:// pubs.acs.org.

\section{AUTHOR INFORMATION}

\section{Corresponding Author}

*Phone: +86 10-62849685; e-mail: LHGuo@rcees.ac.cn.

\section{Notes}

The authors declare no competing financial interest.

\section{ACKNOWLEDGMENTS}

This work was supported by the National Natural Science Foundation of China (nos. 20890112, 20825519, and 20921063).

\section{REFERENCES}

(1) Hooper, K.; McDonald, T. A. The PBDEs: an emerging environmental challenge and another reason for breast-milk monitoring programs. Environ. Health Perspect. 2000, 108, 387-392.

(2) Meneses, M.; Wingfors, H.; Schuhmacher, M.; Domingo, J. L.; Lindström, G.; Van Bavel, B. Polybrominated dipenyl ethers detected in human adipose tissue from Spain. Chemosphere 1999, 39, 22712278 .

(3) Athanasiadou, M.; Cuadra, S. N.; Marsh, G.; Bergman, A.; Jakobsson, K. Polybrominated diphenyl ethers (PBDEs) and bioaccumulative hydroxylated PBDE metabolites in young humans from Managua, Nicaragua. Environ. Health Perspect. 2008, 116, 400-408.

(4) Qiu, X.; Bigsby, R. M.; Hites, R. A. Hydroxylated metabolites of polybrominated diphenyl ethers in human blood samples from the United States. Environ. Health Perspect. 2008, 117, 93-98.

(5) Verreault, J.; Garielsen, G. W.; Chu, S.; Muir, D. C.; Andersen, M.; Hamaed, A.; Letcher, R. J. Flame retardants and methoxylated and hydroxylated polybrominated diphenyl ethers in two Norwegian Arctic top predators: glaucous gulls and polar bears. Environ. Sci. Technol. 2005, 39, 6021-6028.

(6) Wan, Y.; Wiseman, S.; Chang, H.; Zhang, X; Jones, P. D.; Hecker, M.; Kannan, K.; Tanabe, S.; Hu, J.; Lam, M. H.; Giesy, J. P. Origin of hydroxylated brominated diphenyl ethers: natural compounds or manmade flame retardants? Environ. Sci. Technol. 2009, 43, 7536-7542.

(7) Hess, G. Industry to phase out decaBDE. Chem. Eng. News 2009, $87,1$.
(8) Boas, M.; Feldt-Rasmussen, U.; Skakkebaek, N. E.; Main, K. M. Environmental chemicals and thyroid function. Eur. J. Endocrinol. 2006, 154, 599-611.

(9) McDonald, T. A. A perspective on the potential health risks of PBDEs. Chemosphere 2002, 46, 745-755.

(10) Harvey, C. B.; Williams, G. R. Mechanism of thyroid hormone action. Thyroid 2002, 12, 441-448.

(11) Zhou, A.; Wei, Z.; Read, R. J.; Carrell, R. W. Structural mechanism for the carriage and release of thyroxine in the blood. Proc. Natl. Acad. Sci. U.S.A. 2006, 103, 13321-13326.

(12) Blake, C. C.; Geisow, M. J.; Oatley, S. J.; Rérat, B.; Rérat, C. Structure of prealbumin secondary, tertiary and quaternary interactions determined by Fourier refinement at 1.8 A. J. Mol. Biol. 1978, 121, 339-356.

(13) Nilsson, S.; Rask, L.; Peterson, P. A. Studies on thyroid hormone-binding proteins. J. Biol. Chem. 1975, 250, 8554-8563.

(14) Zhou, T.; Taylor, M. M.; DeVito, M. J.; Crofton, K. M. Developmental exposure to brominated diphenyl ethers results in thyroid hormone disruption. Toxicol. Sci. 2002, 66, 105-116.

(15) Lema, S. C.; Dickey, J. T.; Schultz, I. R.; Swanson, P. Dietary exposure to 2,2',4,4'-tetrabromodiphenyl ether (PBDE-47) alters thyroid status and thyroid hormone-regulated gene transcription in the pituitary and brain. Environ. Health Perspect. 2008, 116, 16941699.

(16) Tseng, L. H.; Li, M. H.; Tsai, S. S.; Lee, C. W.; Pan, M. H.; Yao, W. J.; Hsu, P. C. Developmental exposure to decabromodiphenyl ether (PBDE 209): Effects on thyroid hormone and hepatic enzyme activity in male mouse offspring. Chemosphere 2008, 70, 640-647.

(17) Meerts, I. A.; van Zanden, J. J.; Luijks, E. A.; van Leeuwen-Bol, I.; Marsh, G.; Jakobsson, E.; Bergman, A.; Brouwer, A. Potent competitive interaction of some brominated flame retardants and related compounds with human transthyretin in vitro. Toxicol. Sci. 2000, 56, 95-104.

(18) Weiss, J. M.; Andersson, P. L.; Lamoree, M. H.; Leonards, P. E.; van Leeuwen, S. P.; Hamers, T. Competitive binding of poly- and perfluorinated compounds to the thyroid hormone transport protein transthyretin. Toxicol. Sci. 2009, 109, 206-216.

(19) Alexander, N. M.; Jennings, J. F. Analysis for total serum thyroxine by equilibrium competitive protein binding on small, reusable sephadex columns. Clin. Chem. 1974, 20, 553-559.

(20) Marchesini, G. R.; Meulenberg, E.; Haasnoot, W.; Mizuguchi, M.; Irth, H. Biosensor recognition of thyroid-disrupting chemicals using transport proteins. Anal. Chem. 2006, 78, 1107-1114.

(21) Marchesini, G. R.; Meimaridou, A.; Haasnoot, W.; Meulenberg, E.; Albertus, F.; Mizuguchi, M.; Takeuchi, M.; Irth, H.; Murk, A. J. Biosensor discovery of thyroxine transport disrupting chemicals. Toxicol. Appl. Pharmacol. 2008, 232, 150-160.

(22) Ferguson, R. N.; Edelhoch, H.; Saroff, H. A.; Robbins, J.; Cahnmann, H. J. Negative cooperativity in the binding of thyroxine to human serum prealbumint. Biochemistry 1975, 14, 282-289.

(23) Cheng, S. Y.; Pages, R. A.; Saroff, H. A.; Edelhoch, H.; Robbins, $\mathrm{J}$. Analysis of thyroid hormone binding to human serum prealbumin by 8-anilinonaphthalene-1-sulfonate fluorescence. Biochemistry 1977, 16, $3707-3713$.

(24) Cao, J.; Lin, Y.; Guo, L. H.; Zhang, A. Q.; Wei, Y.; Yang, Y. Structure-based investigation on the binding interaction of hydroxylated polybrominated diphenyl ethers with thyroxine transport proteins. Toxicology 2010, 277, 20-28.

(25) Ohno, K.; Fukushima, T.; Santa, T.; Waizumi, N.; Tokuyama, H.; Maeda, M.; Imai, K. Estrogen receptor binding assay method for endocrine disruptors using fluorescence polarization. Anal. Chem. 2002, 74, 4391-4396.

(26) Han, K. C.; Kim, J. H.; Kim, K. H.; Kim, E. E.; Seo, J. H.; Yang, E. G. Identification of farnesoid $\mathrm{X}$ receptor modulators by a fluorescence polarization-based interaction assay. Anal. Biochem. 2010, 398, 185-190.

(27) Zheng, J.; Hashimoto, A.; Putnam, M.; Miller, K.; Koh, T. J. Development of a thyroid hormone receptor targeting conjugate. Bioconjugate Chem. 2008, 19, 1227-1234. 
(28) Smith, D. S. Enhancement fluoroimmunoassay of thyroxine. FEBS Lett. 1977, 77, 25-27.

(29) Lin, Q.; Ruuska, S. E.; Shaw, N. S.; Dong, D.; Noy, N. Ligand selectivity of the peroxisome proliferator-activated receptor alpha. Biochemistry 1999, 38, 185-190.

(30) Gupta, S.; Chhibber, M.; Sinha, S.; Surolia, A. Design of mechanism-based inhibitors of transthyretin amyloidosis: studies with biphenyl ethers and new structural templates. J. Med. Chem. 2007, 50, $5589-5599$.

(31) Hamers, T.; Kamstra, J. H.; Sonneveld, E.; Murk, A. J.; Kester, M. H.; Andersson, P. L.; Legler, J.; Brouwer, A. In vitro profiling of the endocrine-disrupting potency of brominated flame retardants. Toxicol. Sci. 2006, 92, 157-173.

(32) Hamers, T.; Kamstra, J. H.; Sonneveld, E.; Murk, A. J.; Visser, T. J.; Van Velzen, M. J.; Brouwer, A.; Bergman, A. Biotransformation of brominated flame retardants into potentially endocrine-disrupting metabolites, with special attention to 2,2',4,4'-tetrabromodiphenyl ether (BDE-47). Mol. Nutr. Food Res. 2008, 52, 284-298.

(33) Chauhan, K. R.; Kodavanti, P. R.; McKinney, J. D. Assessing the role of ortho-substitution on polychlorinated biphenyl binding to transthyretin, a thyroxine transport protein. Toxicol. Appl. Pharmacol. 2000, 162, 10-21.

(34) Hites, R. A. Polybrominated diphenyl ethers in the environment and in people: a meta-analysis of concentrations. Environ. Sci. Technol. 2004, 38, 945-956.

(35) Schell, L. M.; Gallo, M. V.; Denham, M.; Ravenscroft, J.; DeCaprio, A. P.; Carpenter, D. O. Relationship of thyroid hormone levels to levels of polychlorinated biphenyls, lead, p, p'- DDE, and other toxicants in Akwesasne Mohawk youth. Environ. Health Perspect. 2008, 116, 806-813. 